Nietzschean criticism refocusing to democracy from the ecological reformulation of the political

\title{
Reenfoque de la crítica nietzscheana a la democracia desde la reformulación ecológica de lo político
}

Jorge Manuel José Benítez Martínez

Universidad Nacional de Asunción, Paraguay posidonio@gmail.com

DOI: https://doi.org/10.15366/bp2019.22.013

Bajo Palabra. II Época. No 22. Pgs: 257-270

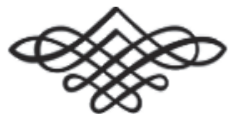


Recibido: 05/05/2018

Aprobado: 02/10/2019

\section{Resumen}

La tesis de este trabajo es que la consideración de lo político desde la perspectiva ecológica, podría matizar la crítica nietzscheana a la democracia, hasta el punto de hacernos percibir una íntima cercanía entre la filosofía profunda de Nietzsche y la democracia, entendida esta como una forma política constituida en el juego del devenir, propio del tejido viviente. Desde su reformulación ecológica, la política democrática no sólo no estaría en contradicción con las ideas políticas del "aristocrático" pensador del devenir sino, al contrario, justamente ella podría ser el medio para lograr la elevación nietzscheana de la vida, y viceversa, la lucha por la realización de ordenes políticos democráticos y de una política que valore la riqueza y la fragilidad de la vida en la Tierra, parece requerir, más que nunca, profundizar su crítica a la democracia y atender a su llamado a recuperar el carácter creador de la política.

Palabras clave: Nietzsche, democracia, ecología, política, vida.

\section{Abstract}

The thesis of this paper is that the consideration of the political from the ecological perspective, could qualify the Nietzschean critique of democracy, to the point of making us perceive an intimate closeness between Nietzsche's philosophy and democracy understood as a constituted political form In the game of becoming, proper to living tissue. Since its ecological reformulation, Democratic politics would not only not be in contradiction with the political ideas of the "aristocratic" thinker of becoming, but, on the contrary It could be the means to achieve the Nietzschean elevation of life, and vice versa, the struggle for the realization of democratic political orders and a policy that values the richness and fragility of life on Earth seems to require, more than never, deepen its critique of democracy and attend to its call to recover the creative nature of politics

Keywords: Nietzsche, democracy, ecology, politics, life.. 
iPermaneced fieles a la Tierra! Antaño los crimenes contra Dios eran los máximos crimenes... Hoy el crimen más terrible es el crimen contra la tierra...

(Asi habló Zaratustra - Prólogo)

\section{Crítica de Nietzsche a la democracia}

PARA UNA ADECUADA INTERPRETACión de la crítica nietzscheana a la democracia debemos contextualizarla históricamente. Sus dardos apuntan a la democracia de su tiempo, la democracia liberal representativa, y sus concomitantes instituciones modernas, a saber: el sufragio universal, los partidos políticos, la opinión pública, la libertad de prensa, etc. en las que se enlazan en retórica contradictoria la idea de soberanía popular con la de los derechos del individuo. Contradicción manifiesta, nos dice Nietzsche, en el hecho de que en la práctica la democracia se reduce a un régimen de dominación que no se distingue de las antiguas formas de gobierno, a no ser por recurrir en gran medida a la demagogia ${ }^{1}$. No obstante, debemos apuntar que en Humano demasiado Humano, tomando a la democracia como proceso histórico más que como un régimen político, Nietzsche sostiene la opinión, acorde con el iluminismo, de que la democratización podría favorecer la emancipación del atávico sometimiento de los individuos a la tradición y, especialmente, a la política tiránica basada en la religión ${ }^{2}$. Curiosamente, esta crítica hoy tendría aun mayor razón de ser, pues, no estaríamos lejos de la verdad, si decimos que la democracia representativa ha devenido en un mero procedimiento formal de legitimación de poderes que no tienen nada de democrático y que, además, desentendiéndose de su origen histórico ha asumido la forma de un universal abstracto que ha funcionado ideológicamente, principalmente en el campo de la política internacional del siglo XX, como lema justificador del ejercicio de la "violencia justa" por parte de Estados abanderados de la democracia sobre otros regímenes y formas de vida supuestamente antidemocráticos.

Pero la crítica más profunda de Nietzsche a la democracia se dirige al efecto inevitable que, como régimen espiritual, tiene en la calidad moral del individuo y, a

\footnotetext{
${ }^{1}$ Nietzsche, F. Escritos sobre retórica, Madrid, Trotta, 2000.

2 Nietzsche, F. Humano Demasiado Humano, Madrid: Akal, 1996, af. 471
} 
la larga, del pueblo. Nietzsche ve que, en la práctica, los valores democráticos de la igualdad y la justicia, tienden a lo que él considera el empequeñecimiento y nivelación del hombre (Mas allá del bien y del Mal) ${ }^{3}$, además de generar un orden político que, tanto amenaza las diferencias individuales en las capacidades interpretativas de la vida, como potencia el carácter gregario y débil de la humanidad (Aurora \&174), transformando al pueblo en un animal de rebaño (Gaya ciencia). Coincidiendo con Tocqueville (La democracia en América), Nietzsche cree que la "igualación de condiciones" conlleva una lenta transformación que vuelve progresivamente semejantes las ideas y sentimientos de los seres humanos. En la sociedad democrática todos los hombres serían parecidos y harían cosas cada vez más parecidas ${ }^{4}$. Pero a diferencia del francés, Nietzsche no cree que esta igualación llevaría a una sociedad liberal, sino más bien, a la creación de las bases psicosociales de una organización política más autoritaria, incluso, que la del Antiguo Régimen. La razón de ello estaría en que la democracia no sería sino un régimen de dominio con una particularidad especial, la de ser tramado y dirigido por los hombres inferiores ( $L a$ voluntad de poder $\$ 856$ ), por aquellos que sólo pueden ser fuertes debilitando a los demás, inoculando en el pueblo el espíritu de resentimiento. Como en Nietzsche la actitud vital propia de los esclavos es el resentimiento, podríamos decir que, paradójicamente, en la democracia dominan los esclavos y los poderosos son los más débiles. Si el resentimiento es el arma de dominio, queda claro para Nietzsche que el vestido moderno e ilustrado de la democracia, no es sino un nuevo disfraz de los valores cristianos, ahora laicizados y traspuestos al terreno político (Humano demasiado humano af. 472). Desde esta perspectiva, el efecto moral de la democracia sería verdaderamente grave; un nihilismo pasivo generador de un hombre promedio, mediocre, incapaz de hacer algo por sí mismo y de crear verdaderamente. La producción de este tipo de hombre mina de raíz a la acción política como acto creador y vital, y la convierte en una práctica de organización administrativa, en la "pequeña política”, preocupada por la mera conservación de la vida, que se limitaría a nivelar la multiplicidad de deseos y posibilidades de una sociedad. En este sentido, Nietzsche ve que la lucha democrática por la igualdad está inextricablemente unida a un peligroso - para la vida- efecto emergente de la modernización: la masificación de la vida humana, vislumbrada como un fenómeno de alcance global ${ }^{5}$. En este proceso se ha impuesto como sentido de la política el ideal del bienestar, definido

\footnotetext{
${ }^{3}$ Nietzsche, F. Mas allá del bien y del mal. Sección octava "Pueblos y patrias" Af. 242

${ }^{4}$ Ver Vernazza, Diego. "El concepto de hombre democrático en Platón, Tocqueville y Nietzsche" Nómadas. Revista Critica de Ciencias Sociales y Juridicas 36 (2012) http://dx.doi.org/10.5209/rev_NOMA.2012.v36.n4.42321

5 Ver Arévalo, Luis "El concepto de gran política desde el concepto de Gran Europa en la obra de Friedrich Nietzsche" Perspectivas internacionales 5. 1 (enero-diciembre 2009): 159-181.
} 
prácticamente como la producción y distribución de las mismas satisfacciones al mayor número de individuos, convirtiendo a las instituciones políticas en simples dispensarios de la sociedad. En democracia todos desean - por igual- el bienestar, el ideal del hombre pequeño. El ciudadano demócrata sería una de las figuras del último hombre, aquel que no puede ver más allá de sus intereses inmediatos y mezquinos, aquel que, sea rico o pobre, burgués o socialista, desea siempre la misma cosa: asegurar a toda costa la posesión de los objetos que satisfagan sus necesidades, en un caso, o sus comodidades, en el otro. Como el comerciante es el intermediario del bienestar así entendido, Nietzsche considera que la democracia está vinculada intrínsecamente a la generalización de la cultura de mercaderes, aquella en la que la búsqueda del mayor beneficio pecuniario se emplea instintiva e indistintamente para todo lo producido, hasta el punto de que el valor del arte, la ciencia, los Estados y hasta de épocas enteras se establece en función de la pregunta por la oferta y la demanda (Aurora). El gran peligro -hoy diríamos, ecológico- que ve Nietzsche en este sino histórico, es que la estirpe del hombre feliz, que llega a su paroxismo en la organización de la sociedad para el consumo, se propaga inconteniblemente, gracias al crecimiento exponencial de la red de medios de transporte y comunicación, como una verdadera infección viral por la Tierra entera, ocasionando, como veremos enseguida, una perturbación ecológica de tal magnitud que la relación hombre-naturaleza, hasta hace poco limitada a los abordajes tan acríticos como interesados de científicos y economistas, ha pasado a un primer plano en el campo de las preocupaciones políticas actuales.

La crítica a la política de baja calidad o pequeña política, revela en el pensador alemán su estima de la política como una dimensión de la acción humana que tendría fines más elevados. Al ideal del bienestar, que domina el sentimiento demócrata, Nietzsche contrapone el de la libertad, entendida esta como la capacidad de decidir en medio de varias posibilidades y construir un modo original de afrontar la vida ${ }^{6}$. Desde la perspectiva nietzscheana la actividad política debería ir más allá de la lucha por la supervivencia o por una vida segura y cómoda, y aplicarse a las decisiones respecto de las posibilidades de los diferentes modos de vida del hombre. La política sería, esencialmente, un instrumento para la organización de la vida pública en vistas a la creación de la cultura más favorable al engrandecimiento y fortalecimiento moral del hombre, en el horizonte de la interminable autocreación humana ${ }^{7}$. Aunque suene extraño, podríamos hablar de una utopía política Nietzscheana: la posibilidad y la lucha por crear un ambiente social perfecto para alcanzar

\footnotetext{
${ }^{6}$ Ver Tongeren, P. A moral da critica de Nietzsche à moral: estudo sobre "Para além de bem e mal". Curitiba: Champagnat, 2012.

7 Ver Delbó, A “Sobre alguns problemas morais da democracia moderna” Cadernos Nietzsche 32 (2013): 149-166.
} 
la nobleza de espíritu, Pero, ¿qué es la nobleza de espíritu? Nobleza se referiría a la actitud y poder de individuos y pueblos que, superando el resentimiento y el temor, son libres de crear valores aptos para acoger toda la complejidad y diversidad de la condición humana. Cabe agregar aquí que Nietzsche, apoyándose en una especie de interpretación lamarckiana de la evolución en la que lo genético no sería lo determinante de la calidad de una especie sino la transmisión cultural de capacidades logradas históricamente, apuesta por la mezcla de razas y civilizaciones para favorecer la elevación de la cultura individual y social. El pueblo de Nietzsche no sería una entidad determinada por la "raza" o alguna propiedad biológica, sino por la experiencia compartida por "los hombres [que] han vivido juntos durante mucho tiempo en condiciones similares de clima, de suelo, de peligro, de necesidades, de trabajo" (Más allá del bien y del Mal af. 268). El ser de un pueblo no sería biológico sino ecológico. En este sentido, por ejemplo, son los Griegos "pre-socráticos" una raza noble, elevada: un pueblo que poseyó el poder apolíneo para organizar el caos dionisiaco ${ }^{8}$ y transformar la verdad de la naturaleza, el ineluctable devenir de todos los seres por el trance de la vida a la muerte y de la muerte a la vida, en la verdad de la sabiduría humana. La tan controvertida expresión nietzscheana "Raza de señores" no haría referencia, entonces, a un grupo determinado por propiedades genéticas, sino a uno distinguido por sus históricas decisiones morales y políticas que se manifestaría en una futura "raza mestiza" de filósofos y artistas que cultivarían un férreo dominio de si (Voluntad de Poder 954) 9

\section{La vida desde la perspectiva ecológica}

ANTES De REFORMUlar lo político desde la perspectiva ecológica intentaremos presentar sintéticamente las ideas fundamentales de la perspectiva ecológica ${ }^{10}$, en las que ya se puede percibir la consonancia de éstas con la filosofía de Nietzsche.

La vida es un fenómeno cósmico en simbiosis con la Tierra. La vida no sólo está en la Tierra, sino que la habita. Entre la Tierra y la Vida hay una historia común de más de 3000 millones de años, muchas de las características de aquella constituyen el resultado de una historia en la que ha intervenido la vida. La casa de la vida, la

\footnotetext{
${ }^{8}$ Ver Consideraciones intempestivas, al final de la segunda parte, sobre el origen de la cultura griega.

9 Kauffmann, Walter "La raza de seńores" en Política, historia y verdad en la obra de Friedrich Nietzsche. Burgos: Huerga y Fierro, 2000, p. 97.

${ }^{10}$ Lo referente a las ideas fundamentales de la perspectiva ecológica se apoyan en la interpretación de la obra del ecólogo Ramón Margalef realizada en mi tesis doctoral, Un modelo ecológico para la reformulación de lo político. Madrid: UAM, 2014. Disponible en https://repositorio.uam.es/.../benitez_\%20martinez_jorge_manuel. pdf?...1
} 
biosfera, es fruto de una paciente y por "momentos" catastrófica autoconstrucción temporal. Para el ecólogo, como para Zaratustra, el mayor crimen que podemos cometer es el crimen contra la Tierra.

La vida es un proceso de transformación continua que se despliega entre lo necesario y lo posible, entre las férreas determinaciones de las leyes de la termodinámica y la posibilidad de variaciones infinitas del juego evolutivo, danzando en una cuerda floja sobre el abismo como el equilibrista de Nietzsche.

Las especies vivientes son fenómenos históricos contingentes. Desde la perspectiva ecológica la especiación es una apuesta por una forma de vida en cuyo éxito se encuentra la garantía de su fracaso. Ecológicamente la especie es un error necesario que, tarde o temprano, se paga con la extinción. Advertir la cualidad temporal y finita de toda afirmación particular en el devenir de la vida, es congruente con la idea nietzscheana de que las verdades son puntos de referencia provisionales y contingentes, útiles solo en determinados espacios y momentos de la historia de los sistemas vivientes.

Las especies no son substancias. La vida es un fenómeno relacional en el que "los organismos vivos, discretos y discontinuos, individualizados orgánicamente, no están aislados funcionalmente, sino vinculados, atravesados y, en definitiva, sostenidos por complejísimas tramas de relaciones" ${ }^{11}$. No son los ecosistemas constituidos por las relaciones entre organismos de diferentes especies, sino las diferentes especies son constituidas por las relaciones ecosistémicas. Así también en el pensamiento nietzscheano no hay lugar para la noción de cosa como substancia o recipiente inmutable de rasgos o propiedades, sino como quanta dinámicos que dan lugar a la realidad en un juego de relaciones de tensión con todos los demás quanta dinámicos (Voluntad de Poder. Crítica del mecanicismo) Las cosas no serían sino efectos de una compleja red de fuerzas en una relación de mutua tensión.

La dinámica ecológica tiende a la complejidad, al refinamiento, en términos nietzscheanos. El universo físico sería el magno sistema histórico de degradación de energía que parte de un hipotético estado uniforme inicial y que tendería a uno cada vez más diferenciado en el que el aumento de entropía, tiene por envés la creación de estructuras más persistentes en el tiempo y de complejidad creciente, las cuales a su vez darían lugar a estructuras secundarias, "como un fuego de artificio que propaga una gran riqueza de formas a escalas cada vez más pequeñas" ${ }^{12}$. Desde la perspectiva ecológica este proceso se manifiesta paradigmáticamente en los sistemas vivientes, tanto en los biológicos como en los culturales, en la forma de aumento de información.

\footnotetext{
${ }_{11}$ Riechmann, Jorge. Un mundo vulnerable: ensayos sobre ecología, ética y tecnociencia. Madrid: Los libros de la catarata, 2005, p. 102.

12 Margalef. Teoría de los sistemas ecológicos. Barcelona: Publicacions Universitat de Barcelona, 1991, p. 86.
} 
La vida como devenir que se autoorganiza. El motor de esta autoorganización sería la relación cibernético-productiva entre información y complejidad. En cualquier sistema material aparecerían interacciones y mecanismos cibernéticos, y en consecuencia acumulación de información. La información se expresaría por un mecanismo, y almacenar información significaría incrementar la complejidad del mismo, a la vez, el incremento de complejidad del mecanismo se podría ver como la tendencia a aumentar la información. Este bucle cibernético sería palmario en los organismos, aunque no se limitaría a ellos ${ }^{13}$.

La autoorganización conduce a sistemas ecológicos más estables. En general, se acepta en ecología que el incremento conjunto de complejidad e información es factor de estabilidad en un sistema. Pero la estabilidad no consistiría en la capacidad de un sistema de mantenerse igual a través del tiempo en relación con un conjunto de referencias, ni en un estado estacionario con ciclos regulares, sino en permanecer dinámicamente en una ruta temporal a la vez determinada e impredecible. La estabilidad sería la "virtud" de un sistema viviente, su potencia de seguir siendo en medio, y por medio de los incesantes cambios cósmicos, gracias a la transformación de parte de la energía que la propia vida degrada irreversiblemente, en información que, a diferencia de la energía, puede acumularse y constituirse en la base de un proceso creador de estructuras. Estas estructuras en la forma de canales, códigos o gramáticas, no solo hacen más eficiente el aprovechamiento de la energía ${ }^{14}$ (sistemas más poderosos) sino también confieren al sistema una mayor capacidad de anticipación, lo que llevaría a aumentar aún más su complejidad (sistemas más sutiles). Interpretando nietzscheanamente este proceso, en la especie humana la tendencia a la estabilidad se realizaría en una cultura caracterizada por una sabia parsimonia que aumentaría la fortaleza vital de individuos y sociedades ante el devenir.

La diversidad como un fenómeno útil a la vida. Los estudios ecológicos sobre la diversidad parecen converger en el establecimiento de una constante: hay relación positiva entre complejidad y diversidad. Un ecosistema suficientemente complejo permite una gran diversidad de comportamientos y maneras de utilizar los recursos, facilitando la coexistencia de mayor variedad de especies, lo que a su vez, aumenta la complejidad del sistema. El sentido de la aparentemente caprichosa e innecesaria

13 Desde la perspectiva ecológica también habrían dispositivos de almacenamiento de información en la naturaleza inorgánica, por ejemplo: en el desarrollo de los meandros de un río, o en la complejidad creciente de la corteza terrestre mediante sucesivas épocas de orogénesis.

${ }^{14}$ Ya en 1924 Vernadsky explicó, en una parte de su libro La Geoquímica, que la energética de la vida era contraria a la energética de la materia bruta. Según Martínez Alier esta diferencia ya había sido seńalada por autores anteriores como el geólogo John Joly y el físico Félix Auerbach y quizás la idea ya existía en los físicos J. R. Mayer, Helmholtz y Kelvin (Martínez Alier, Joan. "Ecología humana y Ecología política” en De la economía ambiental a la economía ecológica Federico Aguilera y Vicent Alcántara. Barcelona: Icaria: FUHEM, 1994, p. 216) 
diversificación de la vida, sería entonces, no sólo de carácter estético, sino también pragmático: toda acumulación de especies proporciona una reserva de variabilidad, que otorga al orden del ecosistema la flexibilidad necesaria para soportar los cambios de las condiciones ambientales sin detrimento de su organización estructural ${ }^{15}$. Por ello la biosfera no es, ni puede ser, una realidad uniforme, sino una realidad que ofrece "naturalmente" una enorme variación en el espacio y el tiempo, que hace imposible encontrar dos partes iguales de la misma, en un grado tal como no existe en el mundo mineral ${ }^{16}$.

La evolución de la vida no es proceso lineal progresivo sino un devenir abierto a la contingencia, y por ello, sujeto a imprevisibles perturbaciones. En el devenir de los sistemas históricos tenemos, no solo cambios progresivos -autoorganizaciónsino también regresivos, aquellos que disparan dinámicas de alta energía que destruyen las estructuras mas complejas de los ecosistemas y los llevan a estadios mas primitivos de organización. Los cambios regresivos se deben a lo que en ecología se denomina "perturbación", a saber: un cambio que ocurre en el interior de un sistema, pero cuyo origen radica en el entorno -en el afuera- del sistema, de modo que, aunque fuera previsible en general, sería siempre imprevisible para el sistema afectado en cuanto al momento preciso de su acontecer. La inevitabilidad de la perturbación significa que siempre es posible lo imprevisible en las entrañas de lo previsible. Un novedoso factor de perturbación sería la expansión planetaria de la organización moderna de la vida humana, basada en una intensa reorganización de su entorno natural a través del desarrollo de un retículo de transporte y comunicación que canaliza y hace disponible energía e información, en cantidad y velocidad crecientes ${ }^{17}$. Este retículo confiere a las sociedades modernas el poder de acelerar el cambio en todos los ecosistemas de la Tierra, perturbándolos sistemáticamente aumentando su tasa de renovación, disminuyendo la diversidad del resto de la biosfera y acelerando la oxidación de la necrósfera (los combustibles fósiles) ${ }^{18}$. En la actualidad el hombre-moderno- es un importantísimo agente de extinción de

\footnotetext{
15 Por otro lado, muchos ecosistemas muestran una diversidad más o menos por debajo de la diversidad "normal", a que tiende la naturaleza. Esto ocurre en los ecosistemas invasores que se están organizando rápidamente, o bien en aquellos que están sometidos a fluctuaciones violentas: en estos casos se manifiesta frecuentemente una competencia brutal y, normalmente, hay alguna especie que saca ventaja de la situación momentánea, deprimiéndose fuertemente la diversidad. Las comunidades perturbadas, contaminadas o sometidas a un pastoreo excesivo, tienden a mostrar diversidades bajas. En este sentido, las actividades del hombre son una perturbación que tienden inexorablemente a disminuir la diversidad de los ecosistemas sobre los que influye, de hecho, la diversidad mínima se observa en el monocultivo humano.

${ }^{16}$ Margalef. Planeta azul, planeta verde. Barcelona: Prensa Científica, 1992, p. 156.

17 Ver Margalef, "Ecological Theory and Prediction in the Study of Interaction between Man and the rest of the Biosphere". Ökologie und Lebensschutz in internationaler sicht. Rombach. Freiburg, (1973): 307 -353, Odum, Howard T. y Odum, Elisabeth. Hombre y Naturaleza: bases energéticas. Barcelona: Omega, 1981.

18 Margalef, Ramón. Teoría de... op. cit. p. 250.
} 
especies, por un lado, es causa de extinción de especies grandes y notorias y otras desconocidas, ligadas a las selvas destruidas ante el avance del "desarrollo", y por el otro, estimula la evolución de especies domésticas y sometidas al cultivo, así como la de muchas plagas que van adquiriendo resistencia a los agentes usados para combatirlas $^{19}$. Si la evolución podría interpretarse como la capacidad de la vida para aprender de las perturbaciones ${ }^{20}$, una siguiente fase en la evolución de la vida humana pasaría necesariamente por aprender de las contradicciones ecológicas de la modernidad y proponer formas alternativas, más estables y mas sabias, de habitar la Tierra.

A todas estas ideas debemos agregar el corolario eco-epistemológico de que el ser humano, aun con todo su poder teórico y técnico es, a la postre, una "parte" de la biósfera y, como tal, sería incapaz por definición de aprehender la razón de la totalidad en la que está inmersa. Por ello lo sensato no sería pretender ser seńores de la Vida sino intentar ser señores de nuestra propia vida.

\section{Reformulación ecológica de la política democrática y su afinidad con la concepción política nietzscheana}

Desde la CONCEPCión ECOLÓGICA DE LA VIDA, un orden político sería un subsistema del ecológico, lo que implica su condición de sistema histórico abierto a la inagotable conflictividad creativa de la vida. Según nuestra interpretación, una política democrática reformulada ecológicamente sería aquella práctica política que, asumiendo radicalmente dicha condición y a diferencia del régimen democrático criticado por Nietzsche, podría ser identificada y distinguida por las siguientes virtudes:

Política del devenir. Lo democrático en la política se realiza precisamente en la puesta en cuestión permanente de toda institucionalización de lo político. Esta actitud evidencia la renuncia a cualquier fundamentación trascendental -metafísica, diría Nietzsche- del orden político y, con ello, a la posibilidad de su cristalización en un régimen político formal-universal definitivo. Por eso, la democracia no está destinada a ser sino más bien a devenir, no a permanecer como un orden instituido de una vez por todas (lo que de hecho la convierte en una mera ideología legitima-

\footnotetext{
${ }_{19}$ Margalef, Ramón. Ecología. Barcelona: Planeta, 1992, p. 53. Según predicciones basadas en el ritmo del crecimiento de la explotación humana de la biosfera, para fines del siglo XXI se habrán extinguido alrededor del $50 \%$ de las especies. (Ver en Leakey, Richard y Lewin, Roger. La Sexta extinción: el futuro de la vida y de la humanidad. Barcelona: Tusquets, 1997, especialmente el capítulo 13).

${ }^{20}$ Con la limitación de que todo aprendizaje nunca es para siempre y de que tampoco se sabe hasta cuándo será útil lo aprendido: en el curso de un proceso típico de asimilación y acumulación de información lo que era peligroso podría convertirse en útil y viceversa.
} 
dora del status quo), sino más bien a metamorfosearse en un constante movimiento de auto-cuestionamiento teórico y de auto-transformación práctica, de manera similar a lo que ocurre en los procesos ecológicos de autoorganización. Desde esta perspectiva, la identidad entre régimen representativo y democracia ya no es válida, pues, la política no sería cosa de una vez (el momento del contrato social) o de algunas veces (los períodos electorales), sino de una continua reevaluación crítica de los ordenes constituidos ante las nuevas circunstancias que acaecen como consecuencia de nuestras mismas decisiones. Por ello, el orden democrático no hace referencia a un régimen de forma definida, sino a un tejido complejo de formas institucionales que se va hilando en el mismo juego de la participación, con una flexibilidad interna a distintos niveles que siempre deja muchos cabos sueltos a ser "atados" por la decisión y acción libres.

Política de la diversidad, de la multiplicidad. En la democracia el ideal de la igualdad y la práctica del disenso aparecen entrelazados en una especie de lógica "cuántica” de complementariedad: la igualdad democrática es la fuente del disenso y en la manifestación del disenso se realiza efectivamente la igualdad democrática. El disenso democrático implica un cambio en los umbrales de percepción que permite nuevas configuraciones del mundo, en las que aparecen como iguales los pueblos y culturas y sus entornos ecológicos, que, de meros medios para la producción económica, pasan a constituirse en sujetos de enunciación y acción políticas.

Politica de la libertad afirmativa. Una política democrática ecológica implica, tanto demostrar la irracionalidad de la racionalidad económica dominante (evidenciándola como un círculo perverso de degradación ambiental y pobreza), como la construcción de racionalidades alternativas a través de la revalorización de otras formas de relación hombre-mundo, capaces de sustentar nuevas articulaciones, entre los sistemas ecológicos y los económico-políticos. Entonces, la democracia ecológica se realizaría no sólo en la protesta respecto de la distribución de bienes materiales, que no se saldría de los límites de la pequeña política, sino sobre todo en la lucha por la asignación de significados valorativos a los bienes, necesidades, ideales, deseos y formas de existencia que definen la interrelación entre sistemas sociales y ecológicos. He aquí que la actitud política nietzscheana de transvaloración se hace patentemente necesaria.

Política de la diferencia. Una democracia ecológica, aplicada a los tiempos de globalización, significaría la posibilidad, el hecho y el derecho de definir el mundo, o mas bien des-definirlo, desde las múltiples prácticas culturales y ecológicas que continúan existiendo precisamente en las culturas marginales, minoritarias, residuales, emergentes, alternativas, disidentes respecto del orden cultural dominante, a pesar de la masificación tecnopolítica -de la "era democrática", según Nietzsche. 
Política de la creatividad. La meta de la ecología política sería la de entender y participar en el ensamblaje de fuerzas que ligan el cambio social, la transformación del medio y el desarrollo científico-técnico, en vistas a una rearticulación de las categorías políticas, más allá de los antiecológicos valores de mercader, denunciados por Nietzsche, que gobiernan la "pequeña política" globalizada. La ecopolítica implica no sólo la necesidad humana, cada vez más urgente, de actuar con prudencia a medida que aumenta el poder científico-tecnológico, sino también la posibilidad de acceder a otros modos de conocer, comprender y valorar a la naturaleza y a nosotros mismos, que nos hagan capaces de apreciar la gran riqueza de formas y matices de nuestra casa cósmica común (oikos) y de obrar (praxis) en consecuencia.

\section{Conclusión}

La reformulación de lo político desde la perspectiva ecológica, nos permite percibir, más allá de la etiqueta "antidemocrática" aplicada frecuentemente al pensamiento de Nietzsche, una íntima cercanía entre su filosofar intempestivo, fiel a la verdad del ser como devenir, y la democracia entendida ecológicamente, como una forma política constituida en el juego del devenir propio del tejido viviente. Desde esta reformulación, la política democrática no sólo no estaría en contradicción con las ideas políticas del "aristocrático" pensador sino al contrario, ella, justamente, podría ser el medio para lograr la elevación nietzscheana de la vida, y viceversa, la lucha por la realización de ordenes políticos democráticos y de una política que valore la riqueza y la fragilidad de la vida en la Tierra, parece requerir, más que nunca, profundizar la crítica de Nietzsche a la democracia y atender a su llamado a recuperar el carácter creador de la política. 


\section{ReferenCias Bibliográficas}

Vernazza, Diego. "El concepto de hombre democrático en Platón, Tocqueville y Nietzsche" Nómadas. Revista Crítica de Ciencias Sociales y Jurídicas 36 (2012) http://dx.doi.org/10.5209/rev_NOMA.2012.v36.n4.42321

Arévalo, Luis "El concepto de gran política desde el concepto de Gran Europa en la obra de Friedrich Nietzsche" Perspectivas internacionales 5.1 (enero-diciembre 2009): 159-181

Tongeren, P. A moral da crítica de Nietzsche à moral: estudo sobre "Para além de bem e mal". Curitiba: Champagnat, 2012.

Delbó, A "Sobre alguns problemas morais da democracia moderna" Cadernos Nietzsche 32 (2013): 149-166 https://doi.org/10.1590/S2316-82422013000100007

Kauffmann, Walter "La raza de señores" en Politica, historia y verdad en la obra de Friedrich Nietzsche. Burgos: Huerga y Fierro, 2000, p. 97.

Riechmann, Jorge. Un mundo vulnerable: ensayos sobre ecología, ética y tecnociencia. Madrid: Los libros de la catarata, 2005, p. 102.

Margalef, Ramón. Ecología. Barcelona: Planeta, 1992, p. 53

Margalef. Planeta azul, planeta verde. Barcelona: Prensa Científica, 1992, p. 156.

Margalef, "Ecological Theory and Prediction in the Study of Interaction between Man and the rest of the Biosphere". Ökologie und Lebensschutz in internationaler sicht. Rombach. Freiburg, (1973): 307 -353

Margalef. Teoría de los sistemas ecológicos. Barcelona: Publicacions Universitat de Barcelona, 1991, p. 86.

Martínez Alier, Joan. "Ecología humana y Ecología política” en De la economía ambiental a la economía ecológica Federico Aguilera y Vicent Alcántara. Barcelona: Icaria: FUHEM, 1994.

Nietzsche, Friedrich. Escritos sobre retórica, Madrid, Trotta, 2000.

Nietzsche, Friedrich. Humano Demasiado Humano, Madrid: Akal, 1996.

Nietzsche, Friedrich. La Voluntad de poder. Madrid: Edaf, 2000.

Nietzsche, F. Mas allá del bien y del mal. Madrid: Alianza, 2012.

Odum, Howard T. y Odum, Elisabeth. Hombre y Naturaleza: bases energéticas. Barcelona: Omega, 1981.

Tocqueville, Alexander. La democracia en América. Madrid: Trotta, 2010.

DOI: https://doi.org/10.15366/bp2019.22.013

Bajo Palabra. II Época. № 22. Pgs: 257-270 
